\title{
Prevalence and antimicrobial susceptibility of gram-negative bacteria isolated from bovine mastitis between 2003 and 2008 in Korea
}

\author{
H. M. Nam, ${ }^{1}$ S. K. Lim, H. M. Kang, J. M. Kim, J. S. Moon, K. C. Jang, J. M. Kim, Y. S. Joo, and S. C. Jung \\ National Veterinary Research and Quarantine Service, 480, Anyang City, Gyeonggi-do, 430-824, Republic of Korea
}

\begin{abstract}
The objective of this study was to assess trends in the prevalence and distribution of gram-negative bacteria isolated from bovine mastitis and their antimicrobial susceptibilities during a 6-yr period between 2003 and 2008 in Korea. Escherichia coli, Pseudomonas fluorescens, Klebsiella pneumoniae, Enterobacter cloacae, Acinetobacter lwoffi/junii, Pseudomonas aeruginosa, and Serratia marcescens were the most commonly observed pathogens during this period. Generally, gramnegative bacteria showed low susceptibilities to most of the antimicrobials tested in this study, except amikacin and gentamicin. Although these 2 aminoglycosides were broadly active against gram-negative bacteria, less than half of those bacteria showed susceptibilities to streptomycin. The $\beta$-lactams, except piperacillin, had the lowest activity among antimicrobials tested in this study. Susceptibilities to chloramphenicol and trimethoprim were fairy high in all genera of gram-negative bacteria, except Acinetobacter spp. and Pseudomonas spp., whereas relatively high resistance to tetracycline was observed uniformly among gram-negative bacteria. There was no significant change in the prevalence of bacterial and the proportion of antimicrobial resistance among gram-negative bacteria isolates during a 6 -yr period.
\end{abstract}

Key words: mastitis, gram-negative bacteria, prevalence, antimicrobial resistance

\section{INTRODUCTION}

Mastitis caused by environmental pathogens such as coliforms and Streptococcus uberis is now the predominant disease in well-managed dairy herds. Although standard mastitis control practices have substantially reduced the incidence of contagious mastitis pathogens, they have been proven ineffective on controlling environmental pathogens (Smith et al., 1985; Hogan and Smith, 2003). It has been previously reported

Received September 23, 2008.

Accepted December 18, 2008.

${ }^{1}$ Corresponding author: namhm@nvrqs.go.kr that more than $25 \%$ of cows in well-managed herds were annually diagnosed with clinical mastitis caused by coliforms, and about $40 \%$ of clinical mastitis cases are caused by gram-negative bacteria (GNB) in the United States and Europe (Hogan and Smith, 2003). The GNB associated with mastitis can be classified into 2 groups, coliforms and noncoliforms. Coliforms such as Citrobacter spp., Enterobacter spp., Escherichia coli, and Klebsiella spp. have been shown to be responsible for approximately half of acute clinical mastitis cases. The most common noncoliforms associated with intramammary infections are Pseudomonas and Serratia (Hogan and Smith, 2003).

High frequency of antimicrobial resistance in GNB has been reported (Lockhart et al., 2007). Because of the endogenous resistance commonly harbored in GNB and the variability among strains, efforts to manage mastitis caused by GNB were often ineffective (Österblad et al., 2000). Antimicrobial agents are widely used for the treatment of bovine mastitis. Antimicrobials currently approved for treatment of bovine mastitis in Korea include tetracycline, sulfa, penicillin, gentamicin, amikacin, fluoroquinolone, cephaloexin, ampicillin, neomycin, streptomycin, kanamycin, amoxicillin, tylosin, lincomycin, cloxacillin, spiramycin, apramycin, and colistin. A better understanding of resistance profiles of GNB associated with mastitis will help understand treatment of the disease caused by those pathogens. Part of the problem is the lack of data on antimicrobial resistance in specific pathogens among GNB, apart from the major coliform mastitis pathogens such as E. coli and Klebsiella pneumoniae (Hogan and Smith, 2003). The objective of this study was to assess trends in the prevalence and distribution of GNB isolated from bovine mastitis and their antimicrobial susceptibility patterns during a 6-yr period from 2003 to 2008 in Korea.

\section{MATERIALS AND METHODS}

\section{Bacteriological Analysis}

A total of 20,386 quarter milk samples from lactating cows on 552 dairy herds nationwide were examined 
Table 1. Species of gram-negative bacteria isolated from milk samples (SCC $>200,000 / \mathrm{mL}$ ) submitted to the Mastitis Diagnostic Laboratory of the National Veterinary Research and Quarantine Service, 2003 to 2008

\begin{tabular}{|c|c|c|c|c|c|c|c|}
\hline Bacterial species & \multicolumn{7}{|c|}{ Number of isolated bacteria (\%) } \\
\hline Pseudomonas fluorescens & $1(0.7)$ & $0(0.0)$ & $1(1.6)$ & $43(20.8)$ & $6(3.2)$ & $8(10.7)$ & $59(7.0)$ \\
\hline Klebsiella pneumoniae & $14(9.3)$ & $13(8.4)$ & $9(14.1)$ & $2(1.0)$ & $14(7.4)$ & $5(6.7)$ & $57(6.7)$ \\
\hline Enterobacter cloacae & $8(5.3)$ & $22(14.2)$ & $4(6.3)$ & $7(3.4)$ & $12(6.3)$ & $1(1.3)$ & $54(6.4)$ \\
\hline Serratia marcescens & $9(6.0)$ & $13(8.4)$ & $5(7.8)$ & $3(1.4)$ & $5(2.6)$ & $3(4.0)$ & $38(4.5)$ \\
\hline Sphingomonas paucimobilis & $12(7.9)$ & $9(5.8)$ & $5(7.8)$ & $7(3.4)$ & $4(2.1)$ & $1(1.3)$ & $38(4.5)$ \\
\hline Acinetobacter calcoaceticus-baumannii complex & $6(4.0)$ & $2(1.3)$ & $0(0.0)$ & $2(1.0)$ & $9(4.8)$ & $0(0.0)$ & $19(2.2)$ \\
\hline Citrobacter freundii complex & $3(2.0)$ & $6(3.9)$ & $1(1.6)$ & $4(1.9)$ & $2(1.1)$ & $1(1.3)$ & $17(2.0)$ \\
\hline Stenotrophomonas maltophila & $6(4.0)$ & $0(0.0)$ & $0(0.0)$ & $3(1.4)$ & $8(4.2)$ & $0(0.0)$ & $17(2.0)$ \\
\hline Pantoea agglomerans & $1(0.7)$ & $1(0.6)$ & $3(4.7)$ & $5(2.4)$ & $3(1.6)$ & $0(0.0)$ & $13(1.5)$ \\
\hline Citrobacter amalonaticus & $2(1.3)$ & $0(0.0)$ & $1(1.6)$ & $7(3.4)$ & $3(1.6)$ & $0(0.0)$ & $13(1.5)$ \\
\hline
\end{tabular}

in the Mastitis Diagnostic Laboratory of the National Veterinary Research and Quarantine Service from January 2003 to June 2008. Milk samples were collected from individual mammary quarters by the herd owner or personnel from the National Veterinary Research and Quarantine Service. Bacterial examination of the samples with SCC of $>200,000$ cells/mL was conducted using standard laboratory techniques (National Mastitis Council, 1990): $10 \mu \mathrm{L}$ of milk was streaked onto a portion of $5 \%$ blood agar plates (Komed, Seoul, Korea) and incubated at 35 to $37^{\circ} \mathrm{C}$ for 18 to $24 \mathrm{~h}$. Plates were observed for growth up to $48 \mathrm{~h}$. Bacteria were identified by colony morphology and Gram stain. Gram-negative bacilli were identified to the species level using the Vitek system (bioMérieux, Hazelwood, MO) as described by the manufacturer.

\section{Antimicrobial Susceptibility Test}

In vitro antimicrobial susceptibility testing was conducted by disc diffusion method of Bauer et al. (1966). For susceptibility testing in GNB, commercially prepared antimicrobial sensitivity discs (BBL; Becton, Dickinson and Company, Cockeysville, MD) having the following 12 antimicrobial agents and concentrations were used: amikacin $(10 \mu \mathrm{g} /$ disk $)$, gentamicin $(10 \mu \mathrm{g} /$ disk), kanamycin (30 $\mu \mathrm{g} /$ disk), streptomycin $(10 \mu \mathrm{g} /$ disk), ampicillin (10 $\mu \mathrm{g} /$ disk $)$, amoxicillin $(20 \mu \mathrm{g} /$ disk), piperacillin $(100 \mu \mathrm{g} /$ disk $)$, cephalothin $(30 \mu \mathrm{g} /$ disk), cefazolin $(30 \mu \mathrm{g} /$ disk $)$, chloramphenicol (30 $\mu \mathrm{g} /$ disk), tetracycline $(30 \mu \mathrm{g} /$ disk $)$, and trimethoprime (5 $\mu \mathrm{g} /$ disk). Isolates were categorized as susceptible, intermediate, or resistant based upon interpretive cri- teria developed by the National Committee for Clinical Laboratory Standards (2002). Escherichia coli ATCC 25922 strain was used as the quality control organism.

\section{RESULTS}

\section{Distribution of GNB Isolates}

A total of 841 GNB were isolated from milk samples examined in this study. The percentages of isolates by species were represented in Table 1. Of 841 isolates, 92 $(10.9 \%)$ could not be identified to species level, and the remaining 749 were identified as a variety of species $(n=66)$ belonging to 32 genera (data are not shown). During the 6-yr period, the most frequently isolated pathogens were E. coli (19.1\%), Pseudomonas fluorescens (7.0\%), K. pneumoniae (6.7\%), Enterobacter cloacae (6.4\%), Acinetobacter lwoffi/junii (6.0\%), Pseudomonas aeruginosa (5.4\%), Serratia marcescens (4.5\%), Sphingomonas paucimobilis (4.5\%), Acinetobacter calcoaceticus-baumannii complex (2.2\%), Citrobacter freundii complex (2.0\%), and Stenotrophomonas maltophila $(2.0 \%)$. These 11 species accounted for $65.8 \%$ of the total number of GNB isolates.

\section{Antimicrobial Susceptibility}

The in vitro susceptibilities of each genus of GNB to 12 antimicrobial agents tested by year are shown in Tables 2-8. Data are provided for E. coli (Table 2) and the other 6 most frequently isolated genera: Klebsiella spp. (Table 3), Enterobacter spp. (Table 4), Serratia spp. (Table 5), Acinetobacter spp. (Table 6), Pseudomonas 
Table 2. Antibacterial susceptibility of Escherichia coli isolated from milk samples (SCC > 200,000/mL) submitted to the Mastitis Diagnostic Laboratory of the National Veterinary Research and Quarantine Service, 2003 to 2008

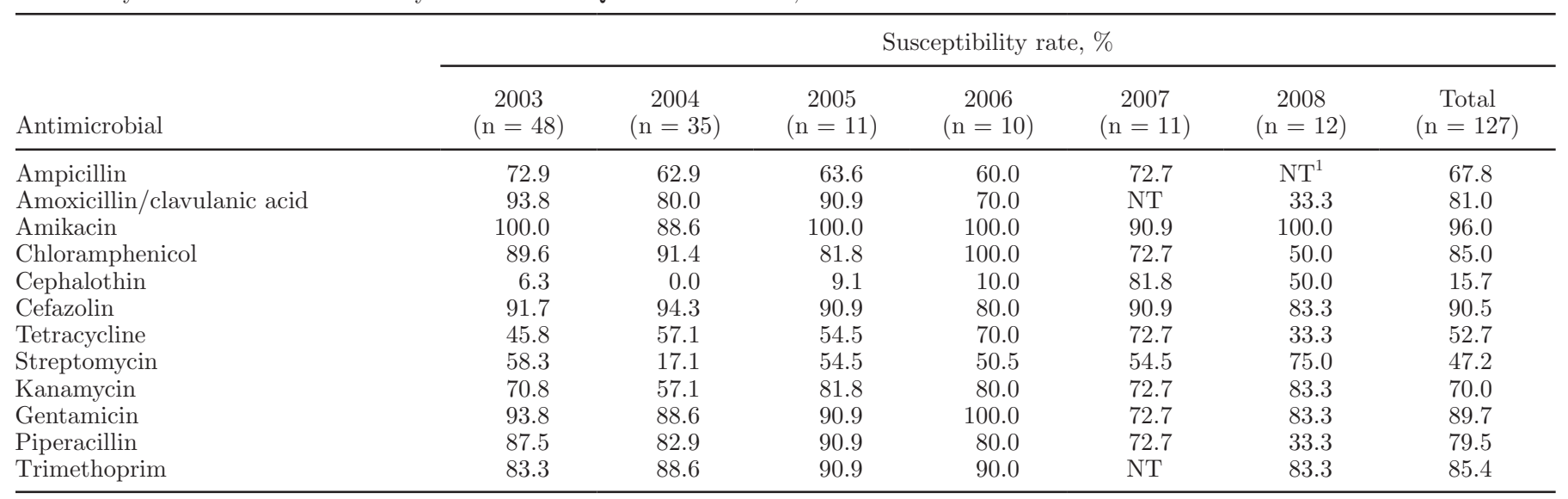

${ }^{1} \mathrm{NT}=$ not tested.

spp. (Table 7), and Citrobacter spp. (Table 8). Overall, no significant change was observed in the proportion of susceptible isolates during the 6-yr period for most of the antimicrobials tested in this study.

In general, amikacin was the most active against all genera of GNB in this study: most isolates (>96\%), apart from Acinetobacter spp. (84.9\%), showed susceptibility to this agent. Although gentamicin and kanamycin also showed relatively high activity against most genera of GNB, streptomycin had fairly low (around $50 \%$ ) activity against most GNB.

The most frequently observed resistance was to cephalothin. Resistance to this drug was observed in most strains of all genera except Klebsiella spp., where $59.2 \%$ of isolates were susceptible. E. coli was relatively susceptible to all antimicrobials but showed an exceptionally low level of susceptibility to cephalothin. The second most commonly observed resistance was against ampicillin; approximately $90 \%$ of Pseudomonas spp., Enterobacter spp., and Klebsiella spp. were resistant to this agent. There was a significant variation of susceptibilities to cefazolin and amoxicillin among genera. For cefazolin, over $80 \%$ of E. coli and Klebsiella spp. were susceptible, whereas only $1.6,2.2$, and $8.8 \%$ of susceptibilities were observed in Enterobacter spp., Serratia spp., and Pseudomonas spp., respectively. Similarly, whereas most E. coli (81\%) and Klebsiella spp. (100\%) isolates were susceptible to amoxicillin, very low susceptibilities were observed in Enterobacter spp. (14.2\%), Serratia spp. (17.0\%), and Pseudomonas spp. (19.1\%), respectively. Among $\beta$-lactams, only piperacillin had relatively high activity against GNB uniformly.

Susceptibilities to chloramphenicol and trimethoprim were high $(>80 \%)$ in all genera of GNB, except Acinetobacter spp. (58.5 and 52.5\%) and Pseudomonas spp. (27.5 and $12.3 \%)$. For tetracycline, relatively high

Table 3. Antibacterial susceptibility of Klebsiella spp. isolated from milk samples (SCC $>200,000 / \mathrm{mL}$ ) submitted to the Mastitis Diagnostic Laboratory of the National Veterinary Research and Quarantine Service, 2003 to 2008

\begin{tabular}{|c|c|c|c|c|c|c|c|}
\hline Antimicrobial & \multicolumn{7}{|c|}{ Susceptibility rate, $\%$} \\
\hline Amoxicillin/clavulanic acid & 100.0 & 100.0 & 100.0 & 100.0 & NT & 100.0 & 100.0 \\
\hline Amikacin & 100.0 & 92.9 & 100.0 & 100.0 & 100.0 & 100.0 & 98.1 \\
\hline Chloramphenicol & 80.0 & 78.6 & 88.9 & 100.0 & 66.7 & 100.0 & 81.4 \\
\hline Streptomycin & 20.0 & 42.9 & 22.2 & 50.0 & 55.6 & 100.0 & 40.7 \\
\hline Kanamycin & 26.7 & 57.1 & 55.6 & 100.0 & 55.6 & 100.0 & 53.7 \\
\hline Gentamicin & 80.0 & 92.9 & 55.6 & 100.0 & 77.8 & 100.0 & 81.4 \\
\hline Piperacillin & 40.0 & 85.7 & 88.9 & 100.0 & 77.8 & 100.0 & 74.0 \\
\hline Trimethoprim & 86.7 & 85.7 & 55.6 & 100.0 & NT & 100.0 & 82.2 \\
\hline
\end{tabular}

${ }^{1} \mathrm{NT}=$ not tested. 
Table 4. Antibacterial susceptibility of Enterobacter spp. isolated from milk samples (SCC > 200,000/mL) submitted to the Mastitis Diagnostic Laboratory of the National Veterinary Research and Quarantine Service, 2003 to 2008

\begin{tabular}{|c|c|c|c|c|c|c|c|}
\hline \multirow[b]{2}{*}{ Antimicrobial } & \multicolumn{7}{|c|}{ Susceptibility rate, \% } \\
\hline & $\begin{array}{c}2003 \\
(\mathrm{n}=10)\end{array}$ & $\begin{array}{c}2004 \\
(\mathrm{n}=27)\end{array}$ & $\begin{array}{c}2005 \\
(\mathrm{n}=5)\end{array}$ & $\begin{array}{c}2006 \\
(\mathrm{n}=6)\end{array}$ & $\begin{array}{c}2007 \\
(\mathrm{n}=11)\end{array}$ & $\begin{array}{c}2008 \\
(\mathrm{n}=1)\end{array}$ & $\begin{array}{c}\text { Total } \\
(\mathrm{n}=60)\end{array}$ \\
\hline Amoxicillin/clavulanic acid & 30.0 & 7.4 & 40.0 & 0.0 & NT & 0.0 & 14.2 \\
\hline Amikacin & 100.0 & 92.6 & 100.0 & 100.0 & 100.0 & 100.0 & 96.6 \\
\hline Chloramphenicol & 60.0 & 92.6 & 100.0 & 100.0 & 100.0 & 100.0 & 90.0 \\
\hline Tetracycline & 60.0 & 88.8 & 100.0 & 100.0 & 100.0 & 100.0 & 88.3 \\
\hline Streptomycin & 70.0 & 59.2 & 60.0 & 83.3 & 72.7 & 100.0 & 66.6 \\
\hline Kanamycin & 70.0 & 63.0 & 100.0 & 83.3 & 100.0 & 100.0 & 76.6 \\
\hline Gentamicin & 80.0 & 96.3 & 100.0 & 100.0 & 100.0 & 100.0 & 93.3 \\
\hline Piperacillin & 90.0 & 100 & 80.0 & 83.3 & 90.9 & 100.0 & 93.3 \\
\hline Trimethoprim & 80.0 & 96.3 & 100.0 & 100.0 & NT & 100.0 & 93.8 \\
\hline
\end{tabular}

${ }^{1} \mathrm{NT}=$ not tested.

resistance was observed uniformly among GNB; about half of E. coli, Klebsiella spp., and Pseudomonas spp., and about $75 \%$ of Serratia spp. were resistant.

\section{DISCUSSION}

There has been national mastitis control program in place since the late 1990s in Korea, which offers laboratory diagnosis and antimicrobial susceptibility testing free of charge to private veterinarians and farmers to aid the control of bovine mastitis and reduce the potential issue of increased antimicrobial resistance. However, mastitis remains one of the most frequently encountered diseases in dairy herds in the country. In this study, we found that a wide variety of GNB (66 species included in 32 genera) were associated with bovine mastitis (data are not shown), although in this paper we have reported only the most prevalent of these. The diversity of GNB was previously observed in mastitic milk (Malinowski et al., 2006) and bulk tank milk samples (Jayarao and Wang, 1999). The finding of E. coli as the most common bacteria among GNB isolates in this study is in agreement with previous studies (Gianneechini et al., 2002; Makovec and Ruegg, 2003; Malinowski et al., 2006). No significant temporal shift in the prevalence of bacterial species was observed, except for P. fluorescens, which has tended, with some fluctuations, to increase over time. The bacterial species most frequently isolated in this study were also found to be the predominant pathogens among GNB isolated from mastitis in previous studies (Lee et al., 2003, 2007; Malinowski et al., 2006).

Recently, a great deal of attention has been paid to GNB because of extensive antibiotic resistance in some species that poses a serious threat to public health (Lockhart et al., 2007). The environment and

Table 5. Antibacterial susceptibility of Serratia spp. isolated from milk samples (SCC $>200,000 / \mathrm{mL}$ ) submitted to the Mastitis Diagnostic Laboratory of the National Veterinary Research and Quarantine Service, 2003 to 2008

\begin{tabular}{|c|c|c|c|c|c|c|c|}
\hline Antimicrobial & \multicolumn{7}{|c|}{ Susceptibility rate, $\%$} \\
\hline Amoxicillin/clavulanic acid & 36.4 & 17.6 & 0.0 & 0.0 & $\mathrm{NT}$ & 0.0 & 17.0 \\
\hline Amikacin & 100.0 & 94.1 & NT & 100.0 & 100.0 & 100.0 & 97.4 \\
\hline Chloramphenicol & 90.9 & 88.2 & 100.0 & 100.0 & 100.0 & 100.0 & 93.3 \\
\hline Streptomycin & 81.8 & 41.2 & 50.0 & 50.0 & 50.0 & 66.7 & 55.6 \\
\hline Kanamycin & 63.6 & 94.1 & 100.0 & 100.0 & 100.0 & 100.0 & 88.9 \\
\hline Gentamicin & 90.9 & 100.0 & 100.0 & 100.0 & 100.0 & 100.0 & 97.8 \\
\hline Piperacillin & 90.9 & 100.0 & 100.0 & 100.0 & 100.0 & 100.0 & 97.8 \\
\hline Trimethoprim & 81.8 & 94.1 & 100.0 & 100.0 & $\mathrm{NT}$ & 100.0 & 92.6 \\
\hline
\end{tabular}

${ }^{1} \mathrm{NT}=$ not tested. 
Table 6. Antibacterial susceptibility of Acinetobacter spp. isolated from milk samples (SCC > 200,000/mL) submitted to the Mastitis Diagnostic Laboratory of the National Veterinary Research and Quarantine Service, 2003 to 2008

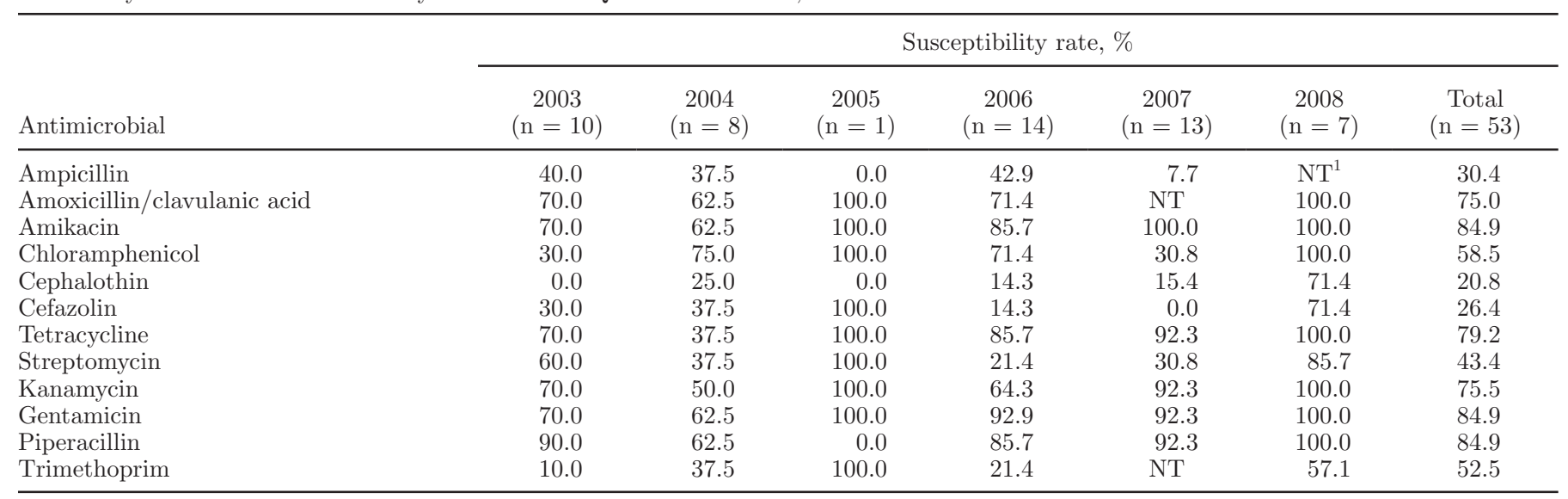

${ }^{1} \mathrm{NT}=$ not tested.

animals on dairy farms could serve as important reservoirs of pathogenic and commensal bacteria (Straley et al., 2006), which often cause udder infection in dairy cattle. Bacteria isolated from coliform mastitis may thus reflect the general resistance situation in the herd and can be considered more as indicator bacteria than as specific pathogens of the udder (Lehtolainen et al., 2003). In this study, we wanted to assess any trends in antimicrobial resistance among GNB isolated from bovine mastitis in Korea between 2003 and 2008. Unexpectedly, we could not find any significant change in the proportion of antimicrobial susceptibilities during a 6 -yr period. Similar findings were observed by previous studies, which reported minimal or little changes in the proportion of resistance in mastitis pathogens during a 4-yr period (Mackie et al., 1988) and a 7-year period (Erskine et al., 2002).
Generally, GNB showed relatively low susceptibilities to most of the antimicrobials tested in this study, except amikacin and gentamicin. These 2 aminoglycosides were the only antimicrobials that were broadly active against GNB. Temperate use of these drugs because of their potential toxicity might be one of the reasons for the low resistance to them. In contrast, less than half of GNB showed susceptibilities to streptomycin, the firstline aminoglycosides antibiotic for use against GNB in large animals.

Most $\beta$-lactams, in particular cephalothin and ampicillin, had the lowest activity against GNB among antimicrobials tested in this study. An exception was piperacillin, to which most of bacteria showed moderate to high susceptibilities. This might be explained by the fact that most of the enterobacteriaceae have intrinsic resistance to $\beta$-lactams by producing $\beta$-lactamases

Table 7. Antibacterial susceptibility of Pseudomonas spp. isolated from milk samples (SCC > 200,000/mL) submitted to the Mastitis Diagnostic Laboratory of the National Veterinary Research and Quarantine Service, 2003 to 2008

\begin{tabular}{|c|c|c|c|c|c|c|c|}
\hline Antimicrobial & \multicolumn{7}{|c|}{ Susceptibility rate, $\%$} \\
\hline Amoxicillin/clavulanic acid & 42.9 & 25.0 & 0.0 & 21.7 & NT & 0.0 & 19.1 \\
\hline Amikacin & 100.0 & 100.0 & NT & 95.7 & 100 & 100.0 & 97.5 \\
\hline Chloramphenicol & 28.6 & 25.0 & 12.5 & 32.6 & 11.1 & 50.0 & 27.5 \\
\hline Streptomycin & 57.1 & 25.0 & 37.5 & NT & 27.8 & 62.5 & 40.0 \\
\hline Kanamycin & 57.1 & 25.0 & 12.5 & 73.9 & 16.7 & 75.0 & 53.8 \\
\hline Gentamicin & 85.7 & 100.0 & 100.0 & 95.7 & 100.0 & 100.0 & 96.7 \\
\hline Piperacillin & 71.4 & 100.0 & 100.0 & 93.5 & 83.3 & 87.5 & 90.1 \\
\hline Trimethoprim & 14.3 & 25.0 & 0.0 & 15.2 & NT & 0.0 & 12.3 \\
\hline
\end{tabular}

${ }^{1} \mathrm{NT}=$ not tested. 
Table 8. Antibacterial susceptibility of Citrobacter spp. isolated from milk samples (SCC > 200,000/mL) submitted to the Mastitis Diagnostic Laboratory of the National Veterinary Research and Quarantine Service, 2003 to 2008

\begin{tabular}{|c|c|c|c|c|c|c|c|}
\hline Antimicrobial & \multicolumn{7}{|c|}{ Susceptibility rate, $\%$} \\
\hline Amoxicillin/clavulanic acid & 45.5 & 83.3 & 60.0 & 60.0 & $\mathrm{NT}$ & 50.0 & 58.8 \\
\hline Amikacin & 100.0 & 100.0 & 80.0 & 100.0 & 100.0 & 100.0 & 97.4 \\
\hline Chloramphenicol & 81.8 & 100.0 & 100.0 & 90.0 & 100.0 & 100.0 & 92.3 \\
\hline Tetracycline & 63.6 & 66.7 & 100.0 & 70.0 & 100.0 & 50.0 & 74.4 \\
\hline Streptomycin & 36.4 & 50.0 & 60.0 & NT & 40.0 & 50.0 & 44.8 \\
\hline Kanamycin & 72.7 & 66.7 & 80.0 & 80.0 & 100.0 & 50.0 & 76.9 \\
\hline Gentamicin & 81.8 & 100.0 & 100.0 & 90.0 & 100.0 & 100.0 & 92.3 \\
\hline Piperacillin & 90.9 & 100.0 & 80.0 & 40.0 & 100.0 & 50.0 & 76.9 \\
\hline Trimethoprim & 81.8 & 100.0 & 100.0 & 90.0 & NT & 50.0 & 88.2 \\
\hline
\end{tabular}

${ }^{1} \mathrm{NT}=$ not tested

(Susić, 2004), but piperacillin is stable against hydrolysis by low-level conventional $\beta$-lactamases from GNB as well as to staphylococcal penicillinases (Livermore, 1998). Although there is a little difference in proportion of resistance among studies, our findings were in agreement with most previous studies conducted in Korea (Kim et al., 2003; Lee et al., 2003, 2007) and other countries (Erskine et al., 2002; Lehtolainen et al., 2003; Neuhauser et al., 2003; Lockhart et al., 2007).

In addition to aminoglycosides and $\beta$-lactams, this study tested tetracycline, chloramphenicol, and trimethoprim, and their activities against GNB varied greatly among bacterial genera. On the whole, relatively high resistance to tetracycline was observed in this study, and our finding was compatible with previous studies conducted in the United States (Erskine et al., 2002; Sawant et al., 2007) and Korea (Lee et al., 2007; Lim et al., 2007). In addition to horizontal transmission of resistant genes (Chopra and Roberts, 2001), the high level of tetracycline resistance in GNB have been linked to tetracycline usage by several studies (Erskine et al., 2002; Sawant et al., 2007). Tetracycline has been one of the most widely used antibiotics in animals (Chopra and Roberts, 2001), and the proportion of tetracyclines accounted for over $50 \%$ of the sales of antimicrobials for animals in Korea (Korean Food and Drug Administration, 2003, 2004). Although chloramphenicol has been withdrawn from use in animals since 1992 in Korea (Korean Food and Drug Administration, 2003), resistance to this drug was still observed in all genera of GNB in this study. The persistence of resistance to chloramphenicol might be explained by cross-resistance to florfenicol (Graham et al., 1998), which is used in cattle for the treatment of respiratory disease and the process of co-selection by other antimicrobials that are used in dairy cattle (Harada et al., 2006). However, a downward trend was observed in the prevalence of resistance to chloramphenicol from 2003 to 2008 in almost all genera of GNB in this study.

Generally, a considerable number (70\%) of all GNB isolates from mastitis had resistance to more than 3 antimicrobials tested in this study (data are not shown). In particular, over $90 \%$ of Pseudomonas spp. showed resistance to almost all antimicrobials except amikacin, gentamicin, and piperacillin. Pseudomonas aeruginosa is intrinsically susceptible to only a limited number of antibacterial agents because of the low permeability of its cell wall; it has also acquired resistance via multiple mechanisms, including production of $\beta$-lactamases and carbapenemases (Lambert, 2002). Consequently, antimicrobial resistance in $P$. aeruginosa is a serious clinical problem, and nosocomial infections caused by multi-drug resistant $P$. aeruginosa are frequently life threatening and often challenging to treat (Streit et al., 2004). The majority of Serratia spp., Enterobacter spp., and Acinetobacter spp. also showed resistance to multiple drugs tested in this study. In this study, we did not examine resistance in individual species of GNB to the antimicrobials that are included in the definition of multi-drug resistance, such as extended-spectrum cephalosporins and ciprofloxacin (Lockhart et al., 2007). Further studies are needed to investigate the possibility of those problematic species originated from bovine mastitis obtaining resistance to other important antimicrobials used in animals and humans.

\section{REFERENCES}

Bauer, A. W., W. M. Kirby, J. C. Sherris, and M. Turck. 1966. Antibiotic susceptibility testing by a standardized single disk method. Am. J. Clin. Pathol. 45:493-496.

Chopra, I., and M. Roberts. 2001. Tetracycline antibiotics: Mode of action, applications, molecular biology, and epidemiology of bacterial resistance. Microbiol. Mol. Biol. Rev. 65:232-260. 
Erskine, R. J., R. D. Walker, C. A. Bolin, P. C. Bartlett, and D. G. White. 2002. Trends in antibacterial susceptibility of mastitis pathogens during a seven-year period. J. Dairy Sci. 85:11111118.

Gianneechini, R., C. Concha, R. Rivero, I. Delucci, and J. Moreno López. 2002. Occurrence of clinical and sub-clinical mastitis in dairy herds in the West Littoral region in Uruguay. Acta Vet. Scand. 43:221-230.

Graham, R., D. Palmer, B. C. Pratt, and C. A. Hart. 1998. In vitro activity of florphenicol. Eur. J. Clin. Microbiol. Infect. Dis. 7:691-694

Harada, K., T. Asai, A. Kojima, K. Ishihara, and T. Takahashi. 2006. Role of coresistance in the development of resistance to chloramphenicol in Escherichia coli isolated from sick cattle and pigs. Am. J. Vet. Res. 67:230-235.

Hogan, J., and K. L. Smith. 2003. Coliform mastitis. Vet. Res. 34:507-519.

Jayarao, B. M., and L. Wang. 1999. A study on the prevalence of gramnegative bacteria in bulk tank milk. J. Dairy Sci. 82:2620-2624.

Kim, C. H., G. S. Kim, J. H. Heo, M. H. Jeong, G. H. Kim, M. H. Jo, G. C. Lee, J. D. Lyu, D. S. Ha, and J. S. Kim. 2003. Isolation and antimicrobial drug susceptibility of mastitic pathogens from dairy cattles with clinical mastitis in Gyeongnam south area. J. Vet. Clin. 20:177-184. (Article in Korean)

Korean Food and Drug Administration. 2003. Establishment of Control System of Antibiotics for Livestocks. Pages 18-39. Korean Food and Drug Administration, Seoul, Korea. (Article in Korean)

Korean Food and Drug Administration. 2004. Establishment of Control System of Antibiotics for Livestock. Pages 19-43. Korean Food and Drug Administration, Seoul, Korea. (Article in Korean)

Lambert, P. A. 2002. Mechanisms of antibiotic resistance in Pseudomonas aeruginosa. J. R. Soc. Med. 95(Suppl. 41):22-26.

Lee, E. S., H. M. Kang, C. I. Chung, and J. S. Moon. 2007. Antimicrobial susceptibility and prevalence of gram-negative bacteria isolated from bovine mastitis. Korean J. Vet. Res. 47:67-75. (Article in Korean)

Lee, J. C., C. Y. Lee, S. G. Kim, J. G. Lee, and G. H. Seo. 2003. Antimicrobial susceptibility of microorganisms isolated from quarter milk samples of Holstein cows. J. Vet. Clin. 20:166-171. (Article in Korean)

Lehtolainen, T., A. Shwimmer, N. Y. Shpigel, T. Honkanen-Buzalski, and S. Pyörälä. 2003. In vitro antimicrobial susceptibility of Escherichia coli isolates from clinical bovine mastitis in Finland and Israel. Acta Vet. Scand. 44:203-205.

Lim, S. K., H. S. Lee, J. R. Byun, S. Y. Park, and S. C. Jung. 2007. Antimicrobial resistance of commensal bacteria isolated from foodproducing animals 1. Antimicrobial resistance of Escherichia coli and Enterococcus spp. isolated from cattle faecal samples. Korean J. Vet. Publ. Hlth. 31:21-29. (Article in Korean)

Livermore, D. M. 1998. $\beta$-Lactamase-mediated resistance and opportunities for its control. J. Antimicrob. Chemother. 41:2541.
Lockhart, S. R., M. A. Abramson, S. E. Beekmann, G. Gallagher, S. Riedel, D. J. Diekema, J. P. Quinn, and G. V. Doern. 2007. Antimicrobial resistance among gram-negative bacilli causing infections in intensive care unit patients in the United States between 1993 and 2004. J. Clin. Microbiol. 45:3352-3359.

Mackie, D. P., E. F. Logan, D. A. Pollock, and S. P. Rodgers. 1988. Antibiotic sensitivity of bovine staphylococcal and coliform mastitis isolates over four years. Vet. Rec. 123:515-517.

Makovec, J. A., and P. L. Ruegg. 2003. Results of milk samples submitted for microbiological examination in Wisconsin from 1994 to 2001. J. Dairy Sci. 86:3466-3472.

Malinowski, E., H. Lassa, A. Kłlossowska, S. Smulski, H. Markiewicz, and M. Kaczmarowski. 2006. Etiological agents of dairy cows mastitis in western part of Poland. Pol. J. Vet. Sci. 9:191-194.

National Committee for Clinical Laboratory Standards. 2002: Performance Standards for Antimicrobial Disk and Dilution Susceptibility Tests for Bacteria Isolated from Animals. 2nd ed. Approved standard. Document M31-A2. National Committee for Clinical Laboratory Standards, Wayne, PA.

National Mastitis Council. 1990: Microbiological procedures for use in the diagnosis of bovine udder infection. National Mastitis Council Inc., Arlington, VA.

Neuhauser, M. M., R. A. Weinstein, R. Rydman, L. H. Danziger, G. Karam, and J. P. Quinn. 2003. Antibiotic resistance among gram-negative bacilli in US intensive care units: Implications for fluoroquinolone use. JAMA 289:885-888.

Österblad, M., A. Hakanen, R. Manninen, T. Leistevuo, R. Peltonen, O. Meurman, P. Huovinen, and P. Kotilainen. 2000. A betweenspecies comparison of antimicrobial resistance in enterobacteria in fecal flora. Antimicrob. Agents Chemother. 44:1479-1484.

Sawant, A. A., N. V. Hegde, B. A. Straley, S. C. Donaldson, C. L. Brenda, J. K. Stephen, and B. M. Jayarao. 2007. Antimicrobialresistant enteric bacteria from dairy cattle. Appl. Environ. Microbiol. 73:156-163.

Smith, K. L., D. A. Todhunter, and P. S. Schoenberger. 1985. Environmental mastitis: Cause, prevalence, prevention. J. Dairy Sci. 68:1531-1553

Straley, B. A., S. C. Donaldson, N. V. Hedge, A. A. Sawant, V. Srinivasan, S. P. Oliver, and B. M. Jayarao. 2006. Public health significance of antimicrobial-resistant gram-negative bacteria in raw bulk tank milk. Foodborne Pathog. Dis. 3:222-233.

Streit, J. M., R. N. Jones, H. S. Sader, and T. R. Fritsche. 2004. Assessment of pathogen occurrences and resistance profiles among infected patients in the intensive care unit: Report from the SENTRY Antimicrobial Surveillance Program (North America, 2001). Int. J. Antimicrob. Agents 24:111-118.

Susić, E. 2004. Mechanisms of resistance in Enterobacteriaceae towards beta-lactamase antibiotics. Acta Med. Croatica 58:307-312. 